\title{
THE DEVELOPMENT OF CVR COATINGS FOR PBR FUELS
}

\author{
R. E. BARLETTA*, P. E. VANIER*, M. B. DOWELL** AND J. A. LENNARTZ** \\ *Brookhaven National Laboratory, Upton, NY 11973. \\ **Advanced Ceramics Corporation, P.O. Box 94924, Cleveland OH 44010.
}

\begin{abstract}
Particle bed reactors (PBRs) are being developed for both space power and propulsion applications. These reactors operate with exhaust gas temperatures in the range of 2500 to $3000 \mathrm{~K}$ and fuel temperatures which may be hundreds of degrees higher. One fuel design for these reactors consists of uranium carbide encapsulated in either carbon or graphite. This fuel kernel must be protected from the coolant gas, usually $\mathrm{H}_{2}$, both to prevent attack of the kernel and to limit fission product release. Refractory caruide coatings have been proposed for this purpose. The typical coating process used for this is a chemical vapor deposition. Testing of other components have indicated the superiority of refractory carbide coatings applied using a chemical vapor reaction (CVR) process, however technology to apply these coatings to large numbers of fuel particles with diameters on the order of $500 \mu \mathrm{m}$ were not readily available.
\end{abstract}

A process to deposit these CVR coatings on surrogate fuel consisting of graphite particles is described. Several types of coatings have been applied to the graphite substrate. These include $\mathrm{NbC}$ in various thicknesses and a bilayer coating consisting of $\mathrm{NbC}$ and $\mathrm{TaC}$ with a intermediate layer of pyrolytic graphite. These coated particles have been characterized prior to test and the results of this characterization will be presented.

\section{INTRODUCTION}

Particle bed reactors (PBRs) are being developed for both space power and propulsion applications. These reactors operate with exhaust gas temperatures in the range of 2500 to $3000 \mathrm{~K}$ and fuel temperatures which may be hundreds of degrees higher. Fuel particle designs have included designs in which the fissile material is encapsulated or surrounded by a layer of free carbon (graphite or pyrocarbon). In order for such fuel to survive, the fuel kernel must be protected from the coolant gas $\left(\mathrm{H}_{2}\right)$ both to prevent attack of the kernel and to limit fission product release. Refractory carbide coatings such as $\mathrm{ZrC}, \mathrm{NbC}$ and $\mathrm{TaC}$ have the potential to provide such protection. It has been found, however, that the performance of the coating is to a large extent dependent upon the details of the coating process. In an effort to produce long-lasting coatings for PBR fuels, various coating processes were tested. One coating type which showed promise in coupon tests were refractory carbide coatings produced by chemical vapor reaction.[1] Technology to apply these coatings to large numbers of fuel particles with diameters on the order of $500 \mu \mathrm{m}$ was not readily available. An effort to prepare such coatings for particulate fuel was initiated as a part of the US Space Nuclear Thermal Propulsion Program. Coatings were produced on surrogate fuel particles and the resulting composite was characterized. The results of this developmental process are presented.

The basic substrate for this work was a batch of graphite particles obtained from Superior Graphite, grade 9400 , identified by the manufacturer as purified spherical graphitic carbon. While the material is referred to by the manufacturer as spherical, it is quite far from it. Rather, it consists

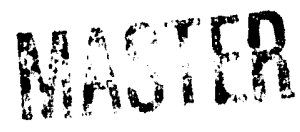


of irregularly shaped particles. Most are rounded but sharp shards are also evident. Given the overall shape of the starting material, and the need for a dense, uniform substrate upon which to deposit subsequent coatings a pyrographite (PG) layer was deposited in a fluidized bed furnace to a nominal thickness of 40 to $45 \mu \mathrm{m}$. This dense outer coating on the particles can be seen from Figure 1 which shows a cross section of two particles. Comparison of the coating and substrate in Figure 1 also shows the open porosity of the graphite substrate. The properties of the PG layer are expected to be similar to other PG coatings and products produced by Advanced Ceramics. PG has been described as "spectroscopically pure carbon [which] approaches theoretical density, is monolithic, free of voids and exceptionally strong."[2] PG coatings produced by this process have a preferred orientation of the crystallites and thus the coating properties are anisotropic.

\section{COATING PROCESS DEVELOPMENT}

Refractory coatings were deposited at subatmospheric pressure in a bed of graphite particles fluidized by argon and the reactant gas used for the deposit. The particle bed itself was contained by an induction-heated cylindrical graphite susceptor. The initial PG undercoatings as well as the PG interlayer coatings were deposited from methane.[3] Metal carbide coatings were prepared by a chemical vapor reaction in which metal halides are disproportionated at high temperatures, yielding conforming monocarbides after reacting with the carbon substrate. The temperature at which metal carbide is formed is $1400^{\circ} \mathrm{C}$ to $2300^{\circ} \mathrm{C}$, depending on the carbide.

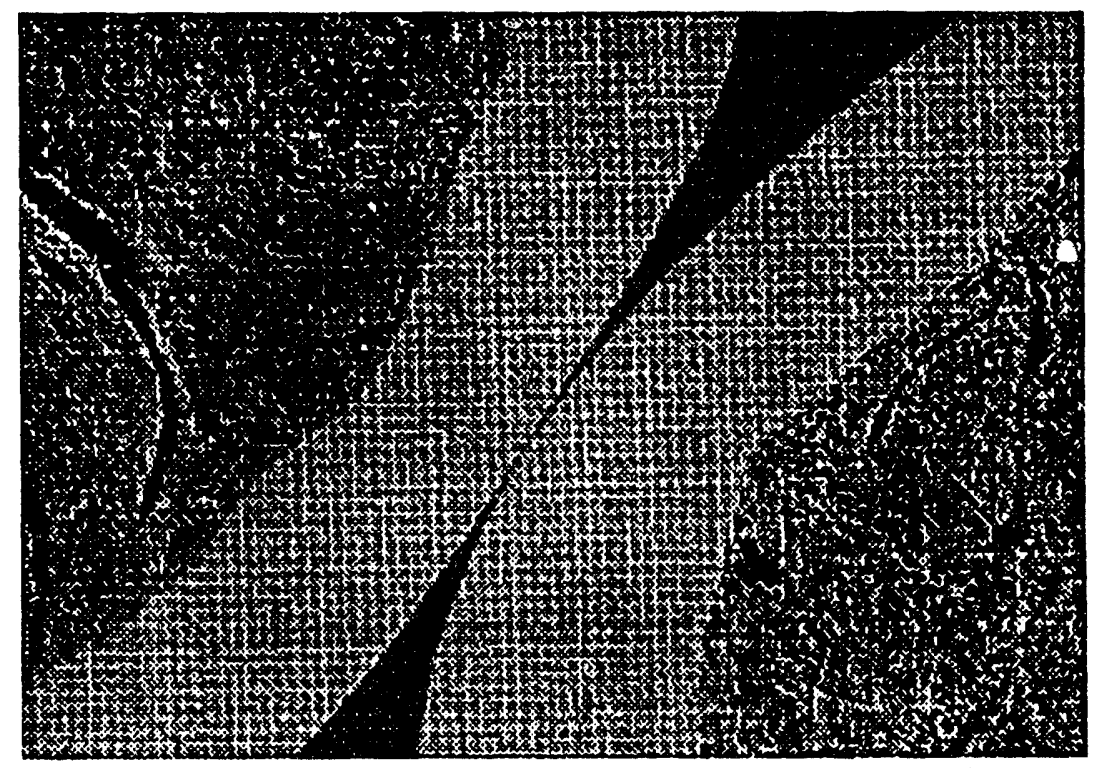

Figure 1. PG coated spherical graphitic carbon particles $(500 \mathrm{X})$.

The metal carbide-coated particles were prepared as follows. The chamber was evacuated while the particle bed was raised to the desired temperature. Niobium or tantalum metal were chlorinated in a separate chamber, and the volatile chlorides were carried by the argon stream into the fluidized bed, where they reacted to form metal carbide coatings on the particles. Reactant flows were terminated and the vacuum chamber was isolated after the desired deposition time had elapsed.

Single and multiple layer coatings were prepared as shown in Table I. Coatings of PG were compared with $\mathrm{PG} / \mathrm{NbC}$ coatings having nominal $\mathrm{Nb}$ thicknesses of $10 \mu \mathrm{m}, 25 \mu \mathrm{m}$ and 40 $\mu \mathrm{m}$, and with a triple layer, $\mathrm{NbC} / \mathrm{PG} / \mathrm{TaC}$, in which the thickness of the outer $\mathrm{TaC}$ layer was 10 $\mu \mathrm{m}$. 
Table 1. Characteristics of as-produced coatings. The coating type and nominal thickness in this table are listed in order from the interior of particle to the exterior.

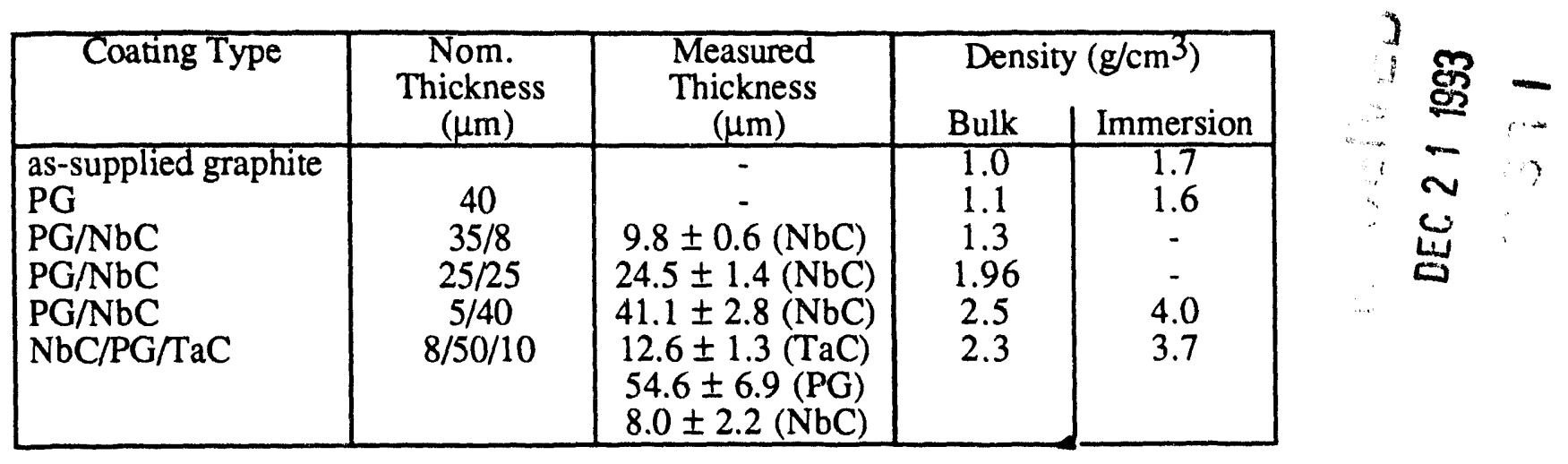

\section{CHARACTERIZATION}

Bulk and immersion densities of the starting material were measured and are given in Table I. In additon, the material obtained from these coating runs was characterized using a variety of techniques. These include grain size measurements, $\mathrm{NbC}$ composition, free carbon and surface area.

\section{Grain Size and Coating Thickness}

SEM and optical microscopy were used to determine average coating thickness and grain size. The measured coating thickness is also given in Table I for the $\mathrm{NbC}, \mathrm{TaC}$ and intermediate PG coatings. Estimates were made of the grain size for the nominal $25 \mu \mathrm{m}$ and $40 \mu \mathrm{m} \mathrm{NbC}$-coated particles only, since for very thin coatings on the order of $10 \mu \mathrm{m}$ the grain size is essentially equivalent to the coating thickness. For the measurement, the etched samples were examined using an optical microscope at a magnification of $200 \mathrm{X}$. These optical images we.e then digitized and imported into an image analysis program, Image 1.4. The optical micrographs were chosen since the etched grain boundaries were more clearly visible. A typical digitized image is shown in Figure 2. To measure the grain size, the image was calibrated to obtain absolute size measurements. For the individual grains, the perimeter was measured. In addition, the major and minor axis of the best fit to an ellipse for the grain was determined. These data were tabulated and processed by sorting the grain measurements into size ranges. The results of this sorting operation were then plotted as histograms for the perimeter, major axis and minor axis. For the nominal $25 \mu \mathrm{m}$ coatings a total of 341 grains on five particles were measured, while, for the nominal $40 \mu \mathrm{m}$ coatings a total of 186 grains on five particles were measured. The data indicate that, for both coating thicknesses, the grains are roughly equiaxial in size. The maxima in both the major and minor and minor histograms are roughly at the same value of around $5 \mu \mathrm{m}$ for the nominal $25 \mu \mathrm{m}$ coating and 10 to 15 microns for the nominal 40 micron coating. Similar values for the grain size can be obtained from the perimeter histograms by which an $8 \mu \mathrm{m}$ grain size is estimated for the nominal $25 \mu \mathrm{m}$ coating and $14 \mu \mathrm{m}$ for the nominal $40 \mu \mathrm{m}$ coating. It should be realized that the methods used here can only approximate the grain size, but the similarity of the results obtained for the two coatings lends support to the conclusion that the process produces large, equiaxial grains roughly $10 \mu \mathrm{m}$ in diameter. 


\section{Composition}

For $\mathrm{NbC}$, the coating composition was determined quantitatively using $\mathrm{X}$-ray diffraction techniques. Samples of $\mathrm{NbC}$ coating from which the carbon had been removed in free carbon determination (see below) were used. The granules from this test were tested as well as powder obtained from crushing these granules. Using the d-spacing, and the Bragg angle, the unit cell spacing was calculated from Bragg's law. For $\mathrm{NbC}$, this parameter was related to the stoichiometry using data available in the literature.[4] At high Bragg angles, the diffraction data on the powder sample converged to a single value for the unit cell which was taken as the most reliable value. For all three $\mathrm{NbC}$ coating thicknesses, a value of $4.466 \pm 0.001$ was obtained. Using the least squares fit of the literature data, a value of $0.95 \pm 0.01$ was obtained for the $\mathrm{C} / \mathrm{Nb}$. This variation in stoichiometry is consistent with the variation of the $\mathrm{X}$-ray data.

\section{Free Carbon}

The amount of free carbon present in the coated particles was measured by reacting the material with hydrogen until a constant weight was obtained. No attempt was made to determine if additional free carbon existed in the carbide coating which may have been unaccessible to reaction with hydrogen. The procedure used was to crush the weighed coated particles in a mortar and pestle to expose the carbon. The sample was heated in hydrogen to a constant weight, reweighed and the percent weight loss, i.e. free carbon, calculated. Three determinations of this value were made for each coating type and thickness. The results of these determinations are given in Table II.

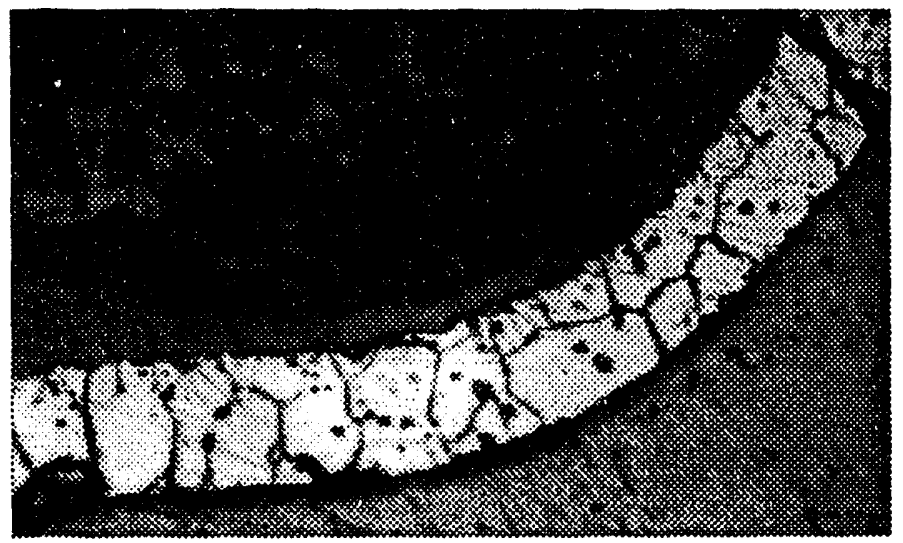

Figure 2. Typical digitized optical image of an etched nominal $40 \mu \mathrm{m} \mathrm{NbC}$ coating used for grain size measurements.

Table II. Free carbon content of as-received coated particles

\begin{tabular}{|l|c|c|}
\hline Coating Type & $\begin{array}{c}\text { Nom. Thickness } \\
(\mathrm{mm})\end{array}$ & $\begin{array}{c}\text { Free Carbon } \\
(\%)\end{array}$ \\
\hline $\mathrm{PG} / \mathrm{NbC}$ & $35 / 8$ & $62 \pm 1$ \\
$\mathrm{PG} / \mathrm{NbC}$ & $25 / 25$ & $37 \pm 1$ \\
$\mathrm{PG} / \mathrm{NbC}$ & $5 / 40$ & $23 \pm 1$ \\
NbC/PG/TaC & $8 / 50 / 10$ & $37 \pm 1$ \\
\hline
\end{tabular}


BET surface area measurements were performed by Quantachrome Corporation on samples of uncoated graphite, $\mathrm{PG}$ coated graphite, as-received $40 \mu \mathrm{m} \mathrm{NbC}$ coated particles, and $\mathrm{TaC} / \mathrm{NbC}$ bilayer coated material. Measurements were made using a multipoint determination of the surface area with krypton gas. The results are listed in Table III. Data from Table 3 indicates a decrease in the available gas surface area with each successive coating step. In addition, the bilayer process resulted in a significant improvement over the niobium carbide coating alone (approximately a factor of three). The surface area available to the gas is a combination of the geometric surface area of the particles themselves plus the surface area due to any open porosity. In order to estimate the relative contributions of each of these types of surface area, an estimate of the geometric surface area is necessary. Since the particles are of irregular shape, only a rough approximation of this value was made as follows. A fractional size distribution was obtained by sieving the particles with mesh sizes of $1000,600,500,425,300$ and $212 \mu \mathrm{m}$. Within each size range, the particles shape was approximated by spheres of a radius equal to the mean of one half the mesh size spread within a cut. For the initial cut ( $1000 \mu \mathrm{m}$ sieve), a particle radius of $600 \mu \mathrm{m}$ was assumed. Using these assumed radii and the fractional weight distribution a weighted average particle radius was calculated. This value could then be used to calculate an "average" particle surface area and volume. By combining these values with the immersion densities given in Table I a geometric surface area $\left(\mathrm{m}^{2} / \mathrm{g}\right)$ can be estimated for comparison with the BET data. These data are also given in Table III.

Table III. Surface area of as-received graphite and , PG, $40 \mathrm{~m} \mathrm{NbC}$, and $\mathrm{TaC} / \mathrm{NbC}$ bilayer coated particles.

\begin{tabular}{|l|c|c|c|}
\hline \multicolumn{1}{|c|}{ Material } & $\begin{array}{c}\text { BET Surface } \\
\text { Area } \\
\left(\mathrm{m}^{2} / \mathrm{g}\right)\end{array}$ & $\begin{array}{c}\text { BET Surface } \\
\text { Area } \\
\left(\mathrm{m}^{2} / \mathrm{cm}^{3}\right)\end{array}$ & $\begin{array}{c}\text { Est. Geom. Surface } \\
\text { Area } \\
(\mathrm{m} 2 / \mathrm{g})\end{array}$ \\
\hline Graphite & $7.789 \times 10^{-1}$ & $7.789 \times 10^{-1}$ & $5.3 \times 10^{-2}$ \\
PG coated graphite & $1.937 \times 10^{-1}$ & $2.131 \times 10^{-1}$ & $6.0 \times 10^{-2}$ \\
$40 \mathrm{~m} \mathrm{NbC}$ particles & $5.486 \times 10^{-2}$ & $1.372 \times 10^{-1}$ & $2.4 \times 10^{-2}$ \\
$\begin{array}{l}\text { TaC/NbC bilayer } \\
\text { particles }\end{array}$ & $1.728 \times 10^{-2}$ & $3.974 \times 10^{-2}$ & $2.5 \times 10^{-2}$ \\
\hline
\end{tabular}

\section{DISCUSSION}

Although no attempt was made to optimize the process for coating fuel particles, the effort to date demonstrates the ability to coat small particles with CVR refractory carbides. Even complicated multilayer coatings can be produced in this fashion. The resulting coatings can be quite dense. For the coated material, the difference between the calculated geometric area and the measured BET surface area is quite small. This is consistent with a lowered porosity. For the bilayer material the measured surface area is less than the estimated geometric surface area. This implies a very low porosity and is more a measure of the accuracy of the estimate. Minimization of the particle surface area and porosity is one factor in limiting both hydrogen attack and fission product release.

With respect to stoichiometry, the composition appears to be slightly to the carbon-rich side of the maximum melting point composition and well above the composition for congruent vaporization $(\mathrm{NbC} 0.748)$. [5] If the carbide were not in contact with the substrate, carbon should be lost upon heating. For fuel particles with at least a minimal PG undercoating, however, this is not a concern. Other testing of carbide coated carbon substrates indicate that carbon loss from the 
substrate occurs upon heating in $\mathrm{H}_{2}$ resulting in undercutting of the coatings. The NbC-C eutectic temperature $(3573 \pm 50 \mathrm{~K})[5]$ is well above anticipated temperature requirements.

The as-received CVR coatings have very large grains. Thus, morphological changes (e.g. grain growth) are not expected upon heating. Sectioning of the fuel after test confirms this assumption. This is in contrast to the changes which occur when fine-grained coatings produced by chemical vapor deposition (CVD) are heated. In this case large, changes in coating structure are seen very quickly (see for example [6]).

\section{CONCLUSIONS}

The development work reported herein demonstrates the practicality of applying CVR coatings of refractory carbides to fuel particles. It must be emphasized that the CVR coating development work has been extremely limited. Complications, such as uranium migration, may occur when actual fuel kernels are exposed to the coating process conditions. Much more work is needed in this area to optimize variables such as the number, type and thickness of the layers used. However, such optimization must be integrated with performance testing of the coating. The results of initial testing of these materials in hydrogen are reported elsewhere in this symposium (Paper N4.3). Further improvements in coating performance might well be realized with additional work.

\section{ACKNOWLEDGEMENTS}

Research performed under funding provided by the US Air Force's Philipps Laboratory Space Nuclear Thermal Propulsion Program, Proposal No. PL-STX-92-006

\section{REFERENCES}

1. R. E. Barletta, P. E. Vanier, J. W. Adams and J. F. Svandrlik, "Carbon Erosion in Hydrogen - The "Midband" Problem Revisited", Tenth Symposium on Space Nuclear Power and Propulsion, M. S. El-Genk and M. D. Hoover, eds., AIP Conference Proceedings 271, CONF930103,1993, p 245.

2. UCAR Advanced Ceramics, Pyrolytic Graphite, Technical Information Bulletin., 1989.

3. J.C. Bockros, in P.L. Walker and P. Thrower, eds., Chemistry and Physics of Carbon, vol.

7, (New York, Marcel Dekker) p. 1, 1969.

4. Gmelin Institute, Gmelin Handbook of Inorganic Chemistry, System Number 49, Nb [B1], Weinheim, Verlag Chemie,1970, p. 353.

5. E. K. Storms [1967], Refractory Carbides, New York, Academic Press, 1967.

6. P. E. Vanier, R. E. Barletta, J. R. Svandrlik and J. Adams, "Tests of Hercules/Ultramet CVD Coatings in Hot Hydrogen", BNL Informal Report, BNL-47965, 1992. 

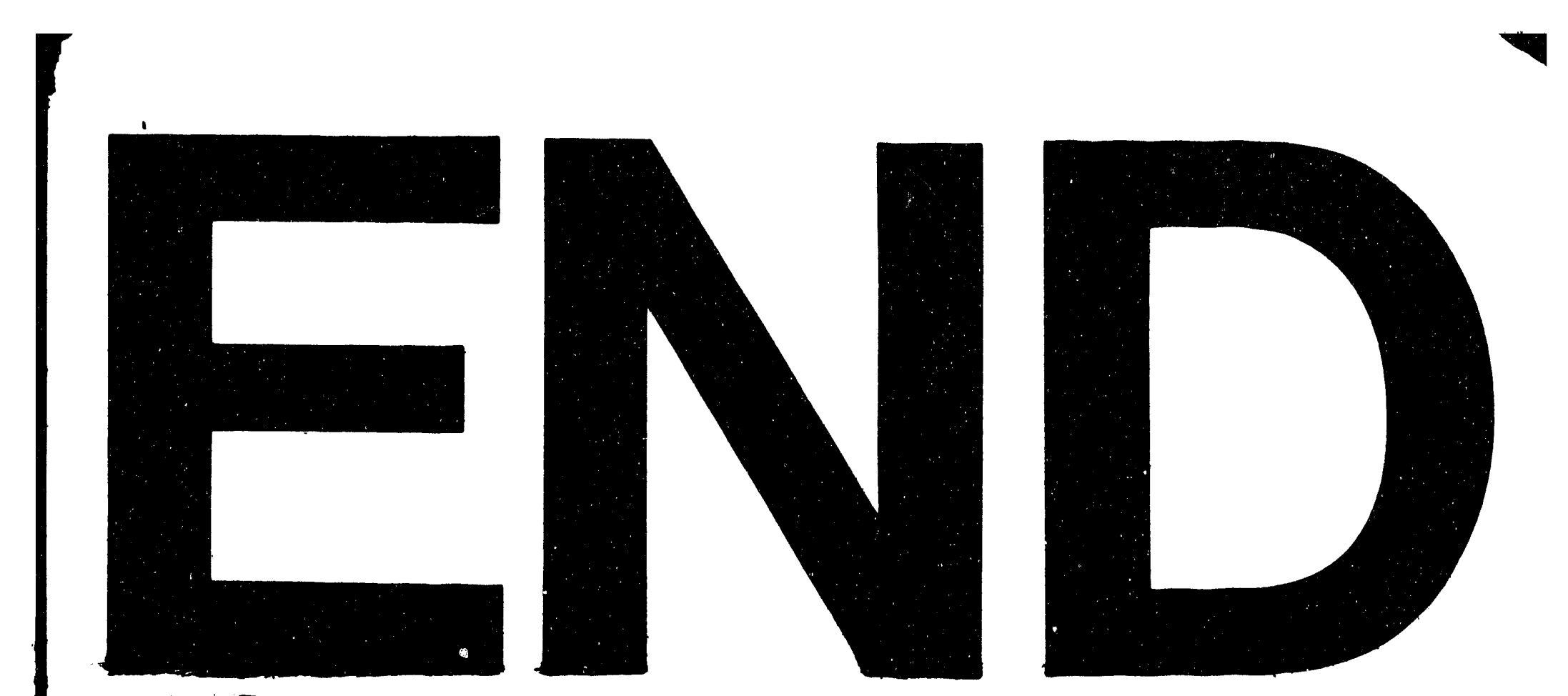

,
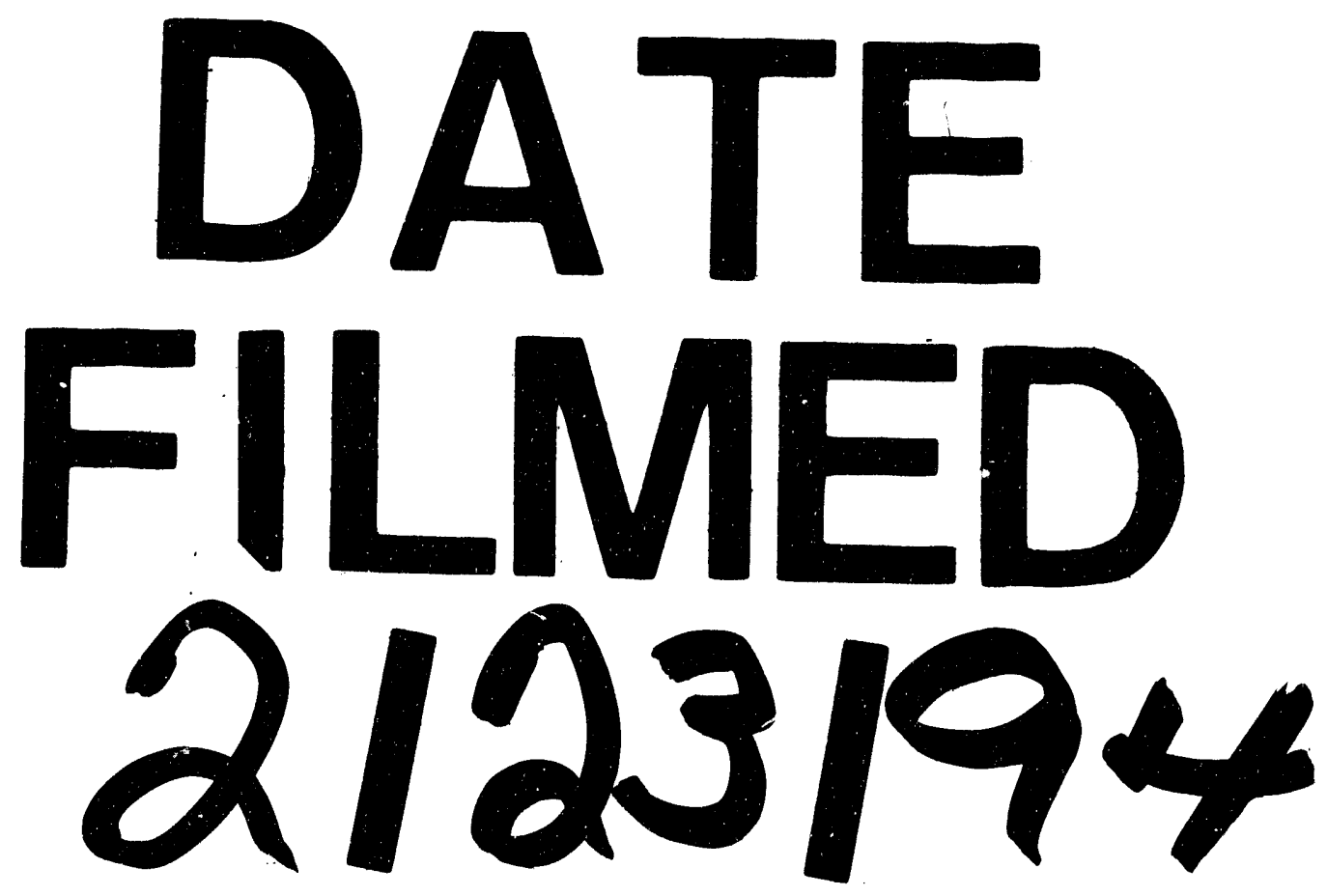

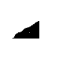


